\title{
Epidemiological association between multiple chemical sensitivity and birth by caesarean section: a nationwide case-control study
}

Kentaro Watai ${ }^{1,2^{*}}$, Yuma Fukutomi ${ }^{1,2}$, Hiroaki Hayashi ${ }^{1}$, Yosuke Kamide ${ }^{1}$, Kiyoshi Sekiya ${ }^{1}$ and Masami Taniguchi ${ }^{1,2}$

\begin{abstract}
Introduction: Multiple chemical sensitivity (MCS) is characterized by recurrent nonspecific symptoms that are attributed to exposure to trace levels of environmental agents. Although the clinical symptoms of MCS have been described in several studies, the risk factors for this condition remain unclear. Our aim was to clarify the risk factors for MCS and the association between MCS and birth by caesarean section.

Methods: We conducted a nationwide case-control study of Japanese individuals (aged 20-65 years) with physician-diagnosed MCS (183 cases) and without MCS (345 controls). The study participants were selected from among 150,000 people in a web-based research panel with approximately 1,000,000 registrants. They completed an online survey including questions on their sociodemographic characteristics, birth history (i.e., birth by caesarean section), and other potential risk factors for MCS. Multivariate logistic regression analysis was employed to determine the association between sociodemographic characteristics and the risk of MCS.

Results: The proportions of case and control subjects who were born by caesarean section were 39.9 and 7.0\%, respectively. The association between birth by caesarean section and MCS was significant even after adjusting for potential confounders (adjusted odds ratio: 6.15; 95\% confidence interval: 3.13-12.1). A history of agricultural work, mouth breathing, $\geq 11$ vaccinations in the past 10 years, and residing in a new home $(<1$ year-old $) \geq 3$ times were also significantly associated with MCS.
\end{abstract}

Conclusion: Our data indicate an epidemiological link between MCS and birth by caesarean section. Moreover, we show that factors other than chemical exposure may be associated with the development of MCS.

Keywords: Multiple chemical sensitivity, Caesarean section, Case-control study, Epidemiology

\section{Background}

Individuals with multiple chemical sensitivity (MCS), also called idiopathic environmental intolerance, exhibit nonspecific multi-organ symptoms after exposure to trace amounts of various chemical substances and/or environmental conditions [1,2]. Although several patient-based studies describe the clinical symptoms of MCS [3, 4], its risk factors remain unclear.

\footnotetext{
* Correspondence: watai.kentaro.bp@mail.hosp.go.jp

${ }^{1}$ Clinical Research Center for Allergy and Rheumatology, National Hospital Organization Sagamihara National Hospital, 18-1 Sakuradai, Minami-ku, Sagamihara, Kanagawa 252-0392, Japan

${ }^{2}$ Course of Allergy and Clinical Immunology, Juntendo University Graduate School of Medicine, Tokyo, Japan
}

In a telephone survey in the United States, the self-reported prevalence of MCS was 12.6-15.9\% [5], whereas the prevalence of physician-diagnosed MCS was 3.1-6.3\% [6]. A population-based study in Germany showed self-reported and physician-diagnosed prevalence rates of MCS of 9.6 and $0.5 \%$, respectively [7]. In Japan, a survey by the National Public Health Institute (now the National Health Science Medicine Institute) in 2000 reported that $0.74 \%$ of adults had MCS [8].

The aim of this study was to elucidate the risk factors for MCS and the association between MCS and birth by caesarean section. Because MCS is relatively rare in the general population and patients with MCS often avoid 
hospitals owing to potential exposure to trace amounts of chemicals en route [5-7], we utilized a case-control study design and recruited subjects from a large-scale web-based research panel. We compared sociodemographic characteristics, birth history, medical history, and environmental exposures between patients with and without MCS.

\section{Methods}

\section{Study design}

We performed a case-control study of Japanese residents aged 20-65 years. Cases and controls were selected from a large-scale web-based panel provided by MACROMILL, INC. (Tokyo, Japan). Members of the research panel are voluntary registrants who agreed to answer various web-based surveys for a small fee (membership points). The number of registered members at the time of this study was approximately 1,000,000; this represents $0.8 \%$ of the Japanese population. The subjects completed a secure online survey that included questions from the Quick Environmental Exposure and Sensitivity Inventory (QEESI; Additional file 1), as well as questions on their sociodemographic characteristics, environmental exposures, and medical histories.

The ethics committee of the Sagamihara National Hospital approved the study protocol (No. 150912, approved on September 15, 2015) in accordance with the Declaration of Helsinki. The study participants' informed consents were obtained when they registered for the web-based study.

\section{Assessment of multiple chemical sensitivity}

The QEESI is the most widely used tool for evaluating MCS. It is both sensitive (92\%) and specific (95\%) for MCS [9-13], and the reliability and validity of the Japanese version of the QEESI have been confirmed [9].

We used the QEESI and a self-reported history of physician-diagnosed MCS to select patients with MCS. The QEESI consists of 50 questions divided into five sections: I) chemical exposures, II) other exposures, III) symptoms, IV) masking index, and V) impact of sensitivities. All sections except IV) (masking index) are scored with a total of 0 to 100 points. MCS risk is based on chemical exposures (section I) and symptoms (section III). Individuals with a total score $\geq 40$ in each of these sections are defined as 'very suggestive of MCS' [11], whereas those with a total score $<40$ are defined as 'not suggestive of MCS'. We included questions in sections I) and III) in our web-based survey.

\section{Web-based survey}

\section{Primary survey}

Figure 1 shows the protocol used for the web-based survey. Between March 17 and March 27, 2016, MACROMILL
INC. sent emails inviting randomly selected, age-stratified research panel registrants to participate in a screening survey. Once 150,000 responses had been obtained, no further invitations were sent. The initial web-based screening questionnaire consisted of three questions (Qs) on MCS (Q1 to Q3) (Additional file 2). Subjects were considered symptomatic physician-diagnosed MCS cases if they met both of the following two criteria: (i) indicated 'MCS' in the response to Q1, 'Which of the diseases listed below have you ever been diagnosed with?' and (ii) provided an affirmative response to Q2, 'Do you have symptoms of MCS now?' Q2 was only asked to subjects who indicated 'MCS' in Q1. Q3 asked if patients were born by caesarian section. For the secondary survey, 500 candidates were randomly selected from among the 972 subjects who fulfilled the two criteria. As controls, 500 age- and sex-matched candidates were chosen from among those who did not indicate 'MCS' in the response to Q1. Consequently, email invitations to the secondary survey were sent to 500 cases and 500 controls.

\section{Secondary survey}

Email invitations to the secondary survey were sent from March 29 to March 31, 2016; reminder emails were sent up to three times. The secondary survey contained detailed questions from sections I) and III) of the Japanese version of the QEESI (Additional file 1) as well as questions on the subjects' sociodemographic characteristics (Additional file 3). It also included questions on the potential risk factors for MCS, namely, comorbidities of allergic diseases, chemical exposures, occupational history, history of vaccinations, number of times of living in a house within 1 year of its construction, birth history, and family history of MCS (Additional file 3).

To ensure the validity of the answers obtained in the primary survey, the secondary survey also included Q1 and Q2 of the primary survey. Of the 500 cases who received an invitation to the secondary survey, 381 responded (response rate, 76\%). We excluded 27 cases with discrepancies in the answers to Q1 and Q2 between the primary and secondary surveys, as well as 171 cases with total scores of $<40$ each in sections I) and III). Of the 500 controls who received an invitation to the secondary survey, 442 responded (response rate, 88\%). We excluded 45 controls with discrepancies in the answers to Q1 and Q2 between the primary and secondary surveys, as well as 52 controls with total scores of $\geq 40$ each in sections I) and III). Finally, data from 183 cases and 345 controls were included in the analyses.

\section{Cases and controls}

To summarize, the cases (MCS patients) in our study (i) were diagnosed with MCS by a physician, (ii) currently had MCS symptoms, and (iii) were classified as 'very suggestive of MCS' in the QEESI (chemical exposures 


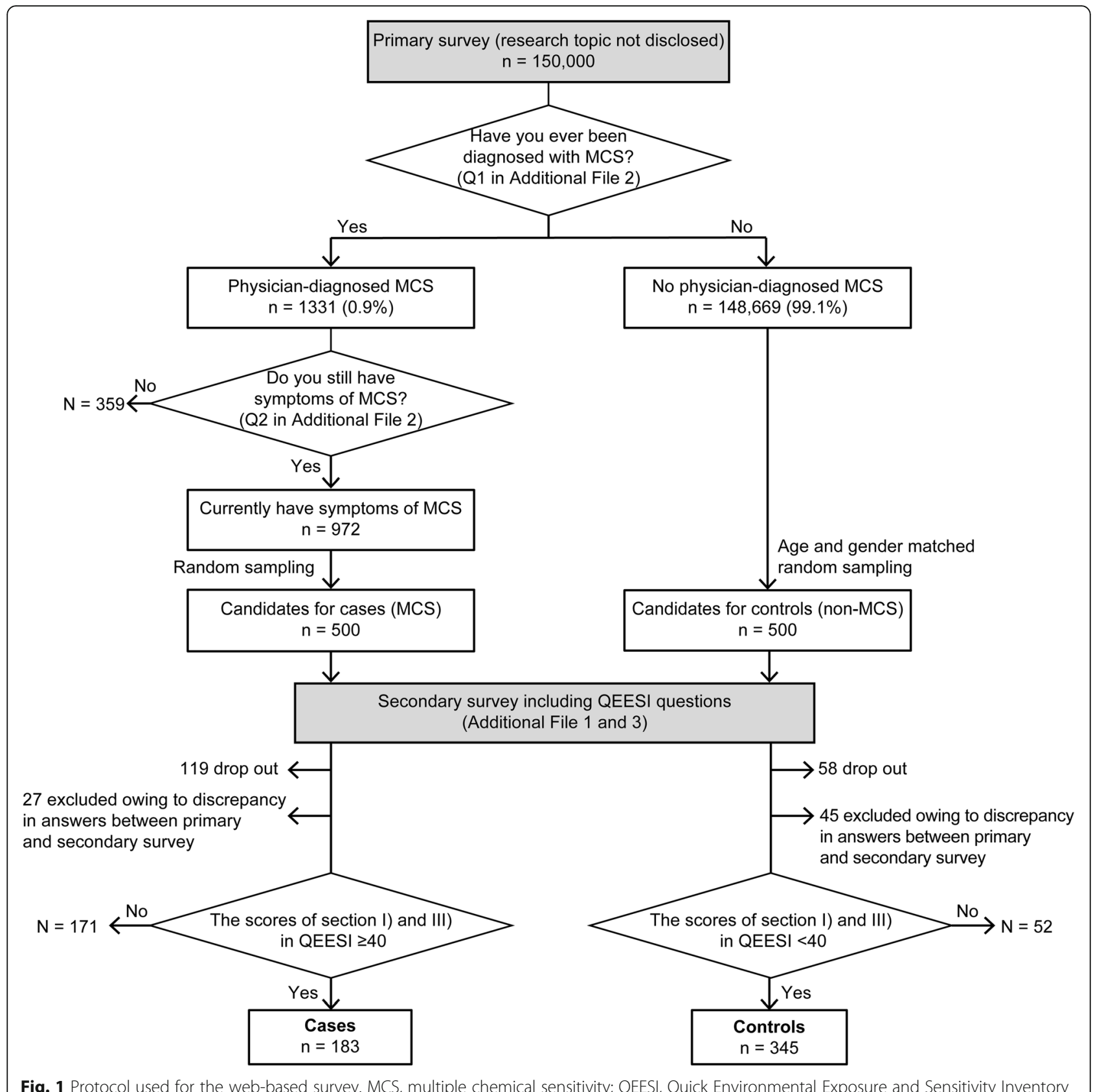

and symptoms scores both $\geq 40$ ) [11]. The controls in our study (i) had never been diagnosed with MCS by a physician, (ii) were age-and sex-matched to the cases, and (iii) were classified as 'not suggestive of MCS' (chemical exposures and symptoms scores both < 40) [11]. The number of cases and controls was 183 and 345 , respectively.

\section{Statistical analysis}

All data were analyzed using SPSS version 22.0 software (IBM, Tokyo, Japan). Categorical variables were compared using the chi-squared or Fisher's exact test, and continuous variables were compared using the T-test or Mann-Whitney U test. Multivariate logistic regression was employed to compare the sociodemographic characteristics of cases and controls and to determine the adjusted odds ratios and 95\% confidence intervals for the association between sociodemographic characteristics and the risk of MCS after adjustments for sex, age, history of smoking, bronchial asthma, and allergic rhinitis. In order, the reasons for these adjustments were as follows: more women have MCS than men; the number of times a person resides in a newly built house is influenced by age; tobacco smoke, a pervasive environmental 
pollutant, worsens MCS symptoms; and bronchial asthma and allergic rhinitis are common in MCS patients [5]. A $P$ value $<0.05$ was considered statistically significant.

\section{Results}

The prevalence of physician-diagnosed MCS in the 150,000 individuals in the primary survey was $0.9 \%$ (Table 1 ). It was significantly higher in men than women in the younger age groups (20-35 years) and significantly higher in women than men in the older age groups (41-65 years).

The sociodemographic characteristics of the 183 cases (subjects with MCS) and 345 controls are shown in Table 2. The questionnaire used to collect these data is described in Additional file 3. The proportion of subjects with a history of smoking was significantly higher in the case group than the control group, as was the incidence of bronchial asthma, allergic rhinitis, metal allergy, fibromyalgia, chronic fatigue syndrome, electromagnetic hypersensitivity, and migraine. The mean age of onset of MCS was $23.6 \pm 12.1$ years.

Birth by caesarean section correlated with MCS. The proportions of subjects who were born by caesarean section were 39.9 and $7.0 \%$ in the case and control groups, respectively $(P<0.001)$. We found a significant association between a family history of MCS and MCS (Table 2). Birth by caesarean section remained significantly associated with MCS in a multivariate logistic regression analysis adjusted for sex, age, history of smoking, bronchial asthma, and allergic rhinitis (adjusted odds ratio: 6.15; 95\% confidence interval: 3.1312.1) (Table 3).

Social/environmental factors also significantly correlated with MCS. As determined via multivariate regression analysis adjusted for the variables listed above, these factors were a history of agricultural work, mouth breathing, residing in a new home (within 1 year of its construction) $\geq 3$ times, and $\geq 11$ vaccinations in the past 10 years (Table 3 ).

\section{Discussion}

To the best of our knowledge, our study is the first to show an epidemiological link between MCS and birth by caesarean section in Japan. Moreover, our data indicate that factors other than chemical exposure may result in the development of MCS.

The prevalence of MCS among the individuals in our study was $0.9 \%$. Interestingly, MCS was significantly more prevalent in men than women in the younger age groups but significantly higher in women than men in

Table 1 Physician-diagnosed multiple chemical sensitivity according to sex and age in the primary survey

\begin{tabular}{|c|c|c|c|}
\hline Age & Men $(N=64,675)$ & Women $(N=85,325)$ & Total $(N=150,000)$ \\
\hline \multirow[t]{2}{*}{$20-25$ years* } & $35 / 1713$ & $64 / 6362$ & $99 / 8075$ \\
\hline & $2.0(1.37-2.71)$ & $1.0(0.76-1.25)$ & $1.2(0.99-1.47)$ \\
\hline \multirow[t]{2}{*}{$26-30$ years* } & $56 / 2746$ & $71 / 11,474$ & $127 / 14,220$ \\
\hline & $2.0(1.51-2.57)$ & $0.6(0.48-0.76)$ & $0.9(0.74-1.05)$ \\
\hline \multirow[t]{2}{*}{ 31-35 years* } & $74 / 4529$ & $115 / 13,769$ & 189/18,298 \\
\hline & $1.6(1.26-2.00)$ & $0.8(0.68-0.99)$ & $1.0(0.89-1.18)$ \\
\hline \multirow[t]{2}{*}{$36-40$ years } & $59 / 6816$ & $117 / 13,079$ & $176 / 19,895$ \\
\hline & $0.9(0.65-1.09)$ & $0.9(0.73-1.06)$ & $0.9(0.75-1.01)$ \\
\hline \multirow[t]{2}{*}{$41-45$ years* } & $60 / 10,311$ & $166 / 13,181$ & $226 / 23,492$ \\
\hline & $0.6(0.44-0.73)$ & $1.3(1.07-1.45)$ & $1.0(0.84-1.09)$ \\
\hline \multirow[t]{2}{*}{$46-50$ years* } & $64 / 10,880$ & $95 / 10,222$ & $159 / 21,102$ \\
\hline & $0.6(0.44-0.73)$ & $0.9(0.74-1.12)$ & $0.8(0.64-0.87)$ \\
\hline \multirow[t]{2}{*}{ 51-55 years* } & $62 / 10,921$ & $93 / 7748$ & $155 / 18,669$ \\
\hline & $0.6(0.43-0.71)$ & $1.2(0.96-1.44)$ & $0.8(0.70-0.96)$ \\
\hline \multirow[t]{2}{*}{$56-60$ years* } & $45 / 8672$ & $61 / 5277$ & $106 / 13,949$ \\
\hline & $0.5(0.37-0.67)$ & $1.2(0.87-1.44)$ & $0.8(0.62-0.90)$ \\
\hline \multirow[t]{2}{*}{$61-65$ years $^{*}$} & 49/8087 & $45 / 4213$ & $94 / 12,300$ \\
\hline & $0.6(0.44-0.78)$ & $1.1(0.76-1.38)$ & $0.8(0.61-0.92)$ \\
\hline \multirow[t]{2}{*}{ Total } & $504 / 64,675$ & $827 / 85,325$ & $1331 / 150,000$ \\
\hline & $0.8(0.71-0.85)$ & $1.0(0.90-1.03)$ & $0.9(0.84-0.93)$ \\
\hline
\end{tabular}

The values in the upper rows represent the number of subjects with multiple chemical sensitivity/the total number of subjects. The values in the lower rows are the percentages ( $95 \%$ confidence intervals)

${ }^{*} P<0.01$, significant difference between men and women using the chi-squared test 
Table 2 Sociodemographic characteristics of cases and controls

\begin{tabular}{|c|c|c|c|}
\hline Variable & Cases (MCS) $n=183$ & Controls (non-MCS) $n=345$ & $P$ value \\
\hline Age (years), mean $\pm S D$ & $39.8 \pm 10.6$ & $40.2 \pm 10.9$ & $0.853^{\ddagger}$ \\
\hline Age at MCS onset (years), mean \pm SD & $23.6 \pm 12.1$ & NA & \\
\hline Female sex, n (\%) & $109(59.6)$ & $200(58.0)$ & 0.724 \\
\hline Body mass index, median (IQR) & $21.1(19.0-23.0)$ & $21.3(19.5-23.9)$ & $0.104^{\S}$ \\
\hline History of smoking, n (\%) & $103(56.3)$ & $127(36.8)$ & $<0.001$ \\
\hline Age at start of smoking (years), mean \pm SD & $21.0 \pm 6.12$ & $19.2 \pm 3.20$ & $0.008^{\ddagger}$ \\
\hline Passive smoking, n (\%) & $106(57.9)$ & $125(36.2)$ & $<0.001$ \\
\hline Birth by caesarean section, $\mathrm{n}(\%)$ & $73(39.9)$ & $24(7.0)$ & $<0.001$ \\
\hline \multicolumn{4}{|l|}{ History of MCS } \\
\hline Patient's mother, n (\%) & $31(16.9)$ & $1(0.3)$ & $<0.001$ \\
\hline Patient's father, n (\%) & $20(10.9)$ & $0(0)$ & $<0.001$ \\
\hline Patient's sibling(s), n (\%) & $35(19.1)$ & $3(0.9)$ & $<0.001$ \\
\hline \multicolumn{4}{|l|}{ Comorbidity, n (\%) } \\
\hline Bronchial asthma & $48(26.2)$ & $9(2.6)$ & $<0.001$ \\
\hline Allergic rhinitis & $119(65.0)$ & $78(22.6)$ & $<0.001$ \\
\hline Metal allergy & $76(41.5)$ & $9(2.6)$ & $<0.001$ \\
\hline Fibromyalgia & $22(12.0)$ & $0(0)$ & $<0.001$ \\
\hline Chronic fatigue syndrome & $25(13.7)$ & $0(0)$ & $<0.001$ \\
\hline Electromagnetic hypersensitivity & $25(13.7)$ & $0(0)$ & $<0.001$ \\
\hline Migraine & $62(33.9)$ & $46(13.3)$ & $<0.001$ \\
\hline \multicolumn{4}{|l|}{ Occupational history, n (\%) } \\
\hline Worker in the manufacturing industry & $43(23.5)$ & $57(16.5)$ & 0.052 \\
\hline Construction worker & $14(7.7)$ & $13(3.8)$ & 0.054 \\
\hline Agricultural worker & $19(10.4)$ & $5(1.4)$ & $<0.001$ \\
\hline Chemical researcher & $6(3.3)$ & $4(1.2)$ & $0.089^{\natural}$ \\
\hline Cosmetics salesperson & $10(5.5)$ & $3(0.9)$ & $0.001^{\natural}$ \\
\hline Shoe store clerk & $10(5.5)$ & $2(0.6)$ & $<0.001^{\natural}$ \\
\hline Healthcare worker & $22(12)$ & $23(6.7)$ & 0.036 \\
\hline Drugstore clerk & $10(5.5)$ & $5(1.4)$ & 0.008 \\
\hline Pet ownership before MCS onset ${ }^{\dagger}$ & $146(79.8)$ & $203(58.8)$ & $<0.001$ \\
\hline Mouth breathing & $126(68.9)$ & $140(40.6)$ & $<0.001$ \\
\hline \multicolumn{3}{|c|}{ Number of vaccinations in the past 10 years, $\mathrm{n}(\%)$} & $<0.001$ \\
\hline 0 & $48(26.2)$ & $162(47.0)$ & \\
\hline $1-5$ & $49(26.8)$ & $111(32.2)$ & \\
\hline $6-10$ & $32(17.5)$ & $56(16.2)$ & \\
\hline$\geq 11$ & $54(29.5)$ & $16(4.6)$ & \\
\hline \multicolumn{3}{|c|}{ Number of times living in a house < 1 year-old, $\mathrm{n}(\%)$} & $<0.001$ \\
\hline 0 & $40(21.9)$ & $138(40.0)$ & \\
\hline $1-2$ & $114(62.3)$ & $198(57.4)$ & \\
\hline$\geq 3$ & $29(15.8)$ & $9(2.6)$ & \\
\hline
\end{tabular}

†Pets include dogs, cats, hamsters, rabbits, guinea pigs, ferrets, and birds but not animals kept for commercial purpose. ${ }^{\ddagger} T$-test. ${ }^{5}$ Mann-Whitney $\mathrm{U}$ test. " $\mathrm{F}$ Fisher's exact test. No symbol, chi-squared test. IQR, interquartile range; MCS, multiple chemical sensitivity; NA, not applicable; SD, standard deviation 
Table 3 Risk factors for multiple chemical sensitivity in a multivariate logistic regression analysis

\begin{tabular}{|c|c|c|}
\hline Variable & Adjusted + OR (95\% Cl) & $P$ value \\
\hline Birth by caesarean section & $6.15(3.13-12.1)$ & $<0.001$ \\
\hline \multicolumn{3}{|l|}{ Occupational history } \\
\hline Agricultural worker & $4.79(1.31-17.6)$ & 0.018 \\
\hline Cosmetics salesperson & $2.31(0.43-12.5)$ & 0.332 \\
\hline Shoe store clerk & $2.46(0.38-16.0)$ & 0.348 \\
\hline Healthcare worker & $1.95(0.84-4.50)$ & 0.119 \\
\hline Drugstore clerk & $2.56(0.54-12.1)$ & 0.236 \\
\hline Pet ownership before MCS onset ${ }^{\ddagger}$ & $1.56(0.90-2.69)$ & 0.115 \\
\hline Mouth breathing & $1.69(1.02-2.80)$ & 0.043 \\
\hline Number of times of living in a house $<1$ year-old & $4.63(1.54-14.0)$ & 0.006 \\
\hline 0 & 1 & \\
\hline $1-2$ & $0.96(0.55-1.67)$ & 0.880 \\
\hline$\geq 3$ & $4.29(1.34-13.7)$ & 0.014 \\
\hline \multicolumn{3}{|l|}{ Number of vaccinations in the past 10 years } \\
\hline 0 & 1 & \\
\hline $1-5$ & $1.26(0.69-2.31)$ & 0.446 \\
\hline $6-10$ & $1.37(0.67-2.80)$ & 0.383 \\
\hline$\geq 11$ & $5.33(2.19-12.9)$ & $<0.001$ \\
\hline
\end{tabular}

${ }^{\dagger}$ Adjusted for sex, age, history of smoking, bronchial asthma, and allergic rhinitis

${ }^{\ddagger}$ Pets include dogs, cats, hamsters, rabbits, guinea pigs, ferrets, and birds but not animals kept for commercial purposes

$\mathrm{Cl}$ confidence interval, MCS multiple chemical sensitivity, OR odds ratio

the older age groups. The reason for this age-based sex difference remains unknown. Although the prevalence of MCS is generally higher in women than men $[5,6]$, no inversion of the sex predominance between younger and older age groups has been reported. The prevalence of MCS in this study is lower than that reported in a large-scale survey in the United Sates $[5,6]$, but about the same as that reported in surveys in Germany [7] and Japan [8].

In our study, the proportion of subjects with a history of smoking was significantly higher in the case (MCS) group than the control group. Although patients with MCS are sensitive to environmental tobacco smoke (ETS) [5], their smoking history and ETS exposure did not correlate with the development of MCS in a previous study [14]. Hence, the association between smoking and MCS requires further research.

Our finding that comorbidities such as allergic diseases were significantly associated with MCS is in agreement with the findings of a survey in the United States [5]. Central sensitization, which involves hyper-excitation of the neurons in the central nervous system due to stimulation from the peripheral nervous system $[15,16]$, has been suggested as a biopsychological explanation for MCS $[17,18]$. MCS, fibromyalgia, chronic fatigue syndrome, and migraine are all considered central sensitization syndromes [17]. Therefore, the association between MCS and comorbidities in this study is likely related to central sensitization.

Birth by caesarean section significantly correlated with MCS in our study even after adjustments for potential confounders. This finding adds to the list of conditions associated with caesarean section. For example, two meta-analyses in 2008 showed a 20\% higher asthma risk in children delivered by caesarean section than in those delivered vaginally $[19,20]$. Although the mechanism is unknown, mothers with MCS are at increased risk of having a child with autism spectrum disorders (ASD) or attention deficit hyperactivity disorder (ADHD) [21]. Infants born by caesarean section are not exposed to the bacteria in the birth canal, which can cause abnormalities in the gut microbiome [22-24]. Owing to the brain-gut interaction, such abnormalities can lead to brain dysfunction [25-27] and perhaps contribute to the development of MCS. Brain sensitivity and central sensitization may also be associated with MCS [17, 18, 28]; central sensitization enhances the activity of the neurons involved in nociception, resulting in hypersensitivity to stimuli $[29,30]$. Abnormalities in the gut microbiome caused by birth by cesarean section might therefore contribute to the development of MCS. Moreover, unlike vaginal delivery, a caesarean section may indirectly expose a fetus or newborn to surgical chemicals (e.g., analgesics and anesthetics administered to the mother). Understanding the mother's 
background and reasons for receiving a caesarean section is necessary to evaluate the influence of caesarean sections on MCS.

Mouth breathing was associated with MCS in our adjusted regression model. Adaption to olfactory hypersensitivity, a characteristic of MCS, may account for mouth breathing in MCS patients [31]. However, the likely association of bronchial asthma and allergic rhinitis with MCS indicates that upper and lower respiratory tract diseases may trigger MCS [5]. Mouth breathing bypasses the protective functions of the nose such as warming, humidifying, and filtering the air [32, 33]. Studies with small sample sizes reported that mouth breathing adversely affected lung function and caused exercise-induced bronchoconstriction in patients with mild asthma [34] and that enforced mouth breathing impaired lung function [35]. Although the causal relationship between mouth breathing and MCS is not clear, it is possible that mouth breathing initiates or exacerbates MCS via comorbidities such as bronchial asthma and allergic rhinitis.

Having been vaccinated $\geq 11$ times in the past 10 years was significantly associated with MCS in our adjusted regression model. Although it would have been ideal to investigate the subjects' entire vaccination history, we considered the recall bias to be large and therefore limited the vaccination history to the last 10 years. To reduce the occurrence of infectious diseases, regular vaccination during childhood is recommended. However, the Vaccine Safety Datalink study showed a significant association between exposure to high levels of mercury in thimerosal-containing children's vaccines and the subsequent risk of atypical autism [36]. Thimerosal is an organomercury preservative that is often added, even today, to multiple-dose vials of many vaccines. In a previous case-control study, maternal chemical intolerance correlated with attention deficit hyperactivity disorder (ADHD) and autism spectrum disorder (ASD) in the offspring (282 AHD cases, 258 ADHD cases, and 154 cases without these disorders) [21]. Although it is not clear how, vaccination and MCS might be linked.

Having lived $\geq 3$ times in a new house (i.e., a house $<1$ year-old) was significantly associated with MCS in our adjusted regression model. Sick building syndrome (SBS) is defined as occupancy-dependent nose, eye, and skin irritations: the symptoms occur within a building but disappear or weaken outside the building. SBS is grouped under the more general definition of MCS/idiopathic environmental intolerance [37]. Indoor environmental factors in a newly built house like inadequate ventilation, high total levels of volatile organic compounds, and dampness could be risk factors for both SBS [38-41] and MCS.

Having been an agricultural worker was significantly associated with MCS in our adjusted regression model.
Such workers are exposed to pesticides [42] when working in recently sprayed fields as well as during the preparation and application of the pesticide [43]. Pesticide exposure is a major health hazard that can lead to various illnesses including respiratory disorders [44-49]. Although the mechanism remains unknown, MCS is often complicated by upper and lower respiratory tract diseases [5]. Exposure to pesticides during agricultural work can affect a worker's respiratory tract and might cause the development of MCS.

This study has several limitations. First, MCS was defined through self-reported physician-diagnosis. However, we ascertained the history of the physician diagnosis by obtaining the name of the hospital or clinic where the MCS diagnosis was made. Moreover, self-reported and actual physician diagnoses have been shown to correlate significantly [5]. Second, no objective measurement was used for diagnosing MCS. Although some studies have identified abnormalities in cerebral blood flow as well as mutations in several genes and metabolic enzymes in MCS [50-53], these are not considered evidence-based indicators of MCS at present. We used the QEESI to define patients with MCS as this tool has been internationally validated [9, 11-13]. Third, we may have overlooked individuals who do not typically access the web; we note that most MCS patients have electromagnetic hypersensitivity [54], which prevents them from using a personal computer. However, some MCS patients have difficulties visiting healthcare facilities owing to potential exposure to chemical substances (such as perfumes and exhaust gases) while on route. A web-based survey can overcome this limitation as the patients do not need to leave their homes.

The main strength of this study was its use of a sizeable web-based survey to identify cases and controls in the general population. Patients with rare diseases are identifiable only in large-scale surveys.

\section{Conclusions}

In conclusion, this study showed an epidemiological link between MCS and birth by caesarean section. Our data also suggest that factors other than chemical exposure may result in the development of MCS.

\section{Additional files}

Additional file 1: Quick Environmental Exposure and Sensitivity Inventory (QEESI) (DOCX $16 \mathrm{~kb}$ )

Additional file 2: Screening questionnaire (DOCX $15 \mathrm{~kb}$ )

Additional file 3: Questionnaire for the secondary survey (DOCX 22 kb)

\section{Abbreviations}

ADHD: Attention deficit hyperactivity disorder; ASD: Autism spectrum disorder; ETS: Environmental tobacco smoke; MCS: Multiple chemical 
sensitivity; Q: Question; QEESI: Quick Environmental Exposure and Sensitivity Inventory; SBS: Sick building syndrome

\section{Acknowledgements}

None

\section{Funding}

This study was supported by a Grant-in-Aid for Evidence-Based Medicine Research from the National Hospital Organization, Japan (no. 2015-EBM-02). The funder had no role in the study design, the collection, analysis, and interpretation of data, the writing of the report, or the decision to submit the article for publication.

\section{Availability of data and materials}

The datasets used in the current study are available from the corresponding author on reasonable request.

\section{Authors' contributions}

$\mathrm{MT}, \mathrm{HH}, \mathrm{KW}$, and YF developed the study concept and design; KW, YK, and KS were responsible for data acquisition; KW, YK, KS, and YF conducted the statistical analyses and contributed to the interpretation of the data; KW wrote the manuscript; YF and MT participated in the critical revision of the manuscript. All authors read and approved the final manuscript.

\section{Ethics approval and consent to participate}

The study participants provided informed consent when they registered for the web-based survey. The ethics committee of the Sagamihara National Hospital approved the study protocol (No. 150912, approved on September 15, 2015), which was in accordance with the Declaration of Helsinki.

\section{Consent for publication}

Not applicable. There are no individual level data in our study.

\section{Competing interests}

The authors declare that they have no competing interests.

\section{Publisher's Note}

Springer Nature remains neutral with regard to jurisdictional claims in published maps and institutional affiliations.

Received: 21 February 2018 Accepted: 5 December 2018 Published online: 14 December 2018

\section{References}

1. American Academy of Allergy Asthma and immunology (AAAAI) Board of Directors. Idiopathic environmental intolerances. J Allergy Clin Immunol. 1999:103:36-40.

2. College of Occupational and Environmental Medicine. ACOEM position statement. Multiple chemical sensitivities: idiopathic environmental intolerance. J Occup Environ Med. 1999;41:940-2.

3. Meggs WJ, Dunn KA, Bloch RM, Goodman PE, Davidoff AL. Prevalence and nature of allergy and chemical sensitivity in a general population. Arch Environ Health. 1996;51:275-82

4. Miller CS. White paper: chemical sensitivity: history and phenomenology. Toxicol Ind Health. 1994;10:253-76.

5. Kreutzer R, Neutra RR, Lashuay N. Prevalence of people reporting sensitivities to chemicals in a population-based survey. Am J Epidemiol. 1999:150:1-12

6. Caress SM, Steinemann AC. Prevalence of multiple chemical sensitivities: a population-based study in the southeastern United States. Am J Public Health. 2004;94:746-7.

7. Hausteiner C, Bornschein S, Hansen J, Zilker T, Forstl H. Self-reported chemical sensitivity in Germany: a population-based survey. Int J Hygiene Environ Health. 2005;208:271-8

8. Uchiyama I, Murayama R. Studies on potential chemical sensitivity in Japan using QEESI sheet [in Japanese]. J Jpn SocAtmos Environ. 2003;44:246-7.

9. Hojo S, Kumano H, Yoshino H, Kakuta K, Ishikawa S. Application of quick environment exposure sensitivity inventory (QEESI) for Japanese population: study of reliability and validity of the questionnaire. Toxicol Industr Health. 2003;19:41-9.
10. Miller CS, Prihoda TJ. A controlled comparison of symptoms and chemical intolerances reported by gulf war veterans, implant recipients and persons with multiple chemical sensitivity. Toxicol Industr Health. 1996;15:386-97.

11. Miller CS, Prihoda TJ. The environmental exposure and sensitivity inventory (EESI): a standardized approach for measuring chemical intolerances for research and clinical applications. Toxicol Ind Health. 1999;15:370-85.

12. Schnakenberg E, Fabig KR, Stanulla M, Strobl N, Lustig M, Fabig N, et al. A cross-sectional study of self-reported chemical-related sensitivity is associated with gene variants of drug-metabolizing enzymes. Environ Health. 2007:6:6

13. Skovbjerg S, Berg ND, Elberling J, Christensen KB. Evaluation of the quick environmental exposure and sensitivity inventory in a Danish population. J Environ Public Health. 2012:304314. https://doi.org/10.1155/2012/304314.

14. Jeong I, Kim I, Park HJ, Roh J, Park JW, Lee JH. Allergic diseases and multiple chemical sensitivity in korean adults. Allergy Asthma Immunol Res. 2014;6: 409-14.

15. Yunus M. The concept of central sensitivity syndromes. In: Wallace DJ, Claw DJ, editors. Fibromyalgia and other central pain syndromes. Lippincott Williams \& Wilkims; 2005. p. 29-44.

16. Yunus M. Central sensitivity syndromes: a unified concept for fibromyalgia and other similar maladies. J Indian Rheum Assoc. 2000;8:27-33.

17. Yunus MB. Fibromyalgia and overlapping disorders: the unifying concept of central sensitivity syndromes. Semin Arthritis Rheum. 2007:36:339-56.

18. Bell IR, Schwartz GE, Baldwin CM, Hardin EE. Neural sensitization and physiological markers in multiple chemical sensitivity. Regul Toxicol Pharmacol. 1996;24:S39-47.

19. Bager $P$, Wohlfahrt J, Westergaard T. Caesarean delivery and risk of atopy and allergic disease: meta-analyses. Clin Exp Allergy. 2008;38:634-42.

20. Thavagnanam S, Fleming J, Bromley A, Shields MD. Cardwell CR. A metaanalysis of the association between caesarean section and childhood asthma. Clin Exp Allergy. 2008;38:629-33.

21. Heilbrun LP, Palmer RF, Jaen CR, Svoboda MD. Perkins J, Miller CS. Maternal chemical and drug intolerances: potential risk factors for autism and attention deficit hyperactivity disorder (ADHD). J Am Board Fam Med. 2015:28:461-70.

22. Goedert JJ, Hua X, Yu G, Shi J. Diversity and composition of the adult fecal microbiome associated with history of cesarean birth or appendectomy: analysis of the American gut project. EBioMedicine. 2014;1:167-72.

23. Jakobsson HE, Abrahamsson TR, Jenmalm MC, Harris K, Quince C, Jernberg

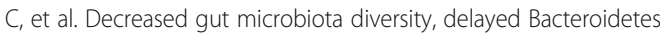
colonisation and reduced Th1 responses in infants delivered by caesarean section. Gut. 2014;63:559-66.

24. Yasmin F, Tun HM, Konya TB, Guttman DS, Chari RS, Field CJ, et al. Cesarean section, formula feeding, and infant antibiotic exposure: separate and combined impacts on gut microbial changes in later infancy. Front Pediatr. 2017:5:200.

25. Collins SM, Surette M, Bercik P. The interplay between the intestinal microbiota and the brain. Nat Rev Microbiol. 2012;10:735-42.

26. Cryan JF, Dinan TG. Mind-altering microorganisms: the impact of the gut microbiota on brain and behaviour. Nat Rev Neurosci. 2012:13:701-12.

27. Dinan TG, Cryan JF. The impact of gut microbiota on brain and behaviour: implications for psychiatry. Curr Opin Clin Nutr Metab Care. 2015:18:552-8.

28. Tran MT, Arendt-Nielsen L, Kupers R, Elberling J. Multiple chemical sensitivity: on the scent of central sensitization. Int J Hygiene Environ Health. 2013;216:202-10.

29. Curatolo M. Central sensitization: Nice to know? Eur J Pain. 2018;22:214-5.

30. Undem BJ, Taylor-Clark T. Mechanisms underlying the neuronal-based symptoms of allergy. J Allergy Clin Immunol. 2014;133:1521-34.

31. Chiaravalloti A, Pagani M, Micarelli A, Di Pietro B, Genovesi G, Alessandrini M, et al. Cortical activity during olfactory stimulation in multiple chemical sensitivity: a (18)F-FDG PET/CT study. Eur J Nucl Med Mol Imaging. 2015;42:733-40.

32. Drettner B, Kumlien J. Experimental studies of the human nasal airconditioning capacity. Acta Otolaryngol. 1981;91:605-9.

33. Naclerio RM, Pinto J, Assanasen P, Baroody FM. Observations on the ability of the nose to warm and humidify inspired air. Rhinology. 2007:45:102-11.

34. Shturman-Ellstein R, Zeballos RJ, Buckley JM, Souhrada JF. The beneficial effect of nasal breathing on exercise-induced bronchoconstriction. Am Rev Respir Dis. 1978;118:65-73

35. Hallani M, Wheatley JR, Amis TC. Enforced mouth breathing decreases lung function in mild asthmatics. Respirol. 2008;13:553-8.

36. Geier DA, Kern JK, Geier MR. Increased risk for an atypical autism diagnosis following thimerosal-containing vaccine exposure in the United States: a 
prospective longitudinal case-control study in the vaccine safety datalink. J Trace Elem Med Biol. 2017:42:18-24.

37. De Luca C, Raskovic D, Pacifico V, Thai JC, Korkina L. The search for reliable biomarkers of disease in multiple chemical sensitivity and other environmental intolerances. Int J Environ Res Public Health. 2011;8:2770-97.

38. Fisk WJ, Mirer AG, Mendell MJ. Quantitative relationship of sick building syndrome symptoms with ventilation rates. Indoor Air 20019. 19:159-65.

39. Norback $D$, Nordstrom $\mathrm{K}$. Sick building syndrome in relation to air exchange rate, $\mathrm{CO}_{2}$, room temperature and relative air humidity in university computer classrooms: an experimental study. Int Arch Occup Environ Health. 2008:82:21-30.

40. Takeda M, Saijo Y, Yuasa M, Kanazawa A, Araki A, Kishi R. Relationship between sick building syndrome and indoor environmental factors in newly built Japanese dwellings. Int Arch Occup Environ Health. 2009;82:583-93.

41. Wang BL, Takigawa T, Yamasaki Y, Sakano N, Wang DH, Ogino K. Symptom definitions for SBS (sick building syndrome) in residential dwellings. Int J Hygiene Environ Health. 2008;211:114-20.

42. Strong LL, Thompson B, Coronado GD, Griffith WC, Vigoren EM, Islas I. Health symptoms and exposure to organophosphate pesticides in farmworkers. Am J Industr Med. 2004;46:599-606.

43. Damalas CA, Eleftherohorinos IG. Pesticide exposure, safety issues and risk assessment indicators. Int J Environ Res Public Health. 2011:8:1402-19.

44. Colosio C, Birindelli S, Corsini E, Galli CL, Maroni M. Low level exposure to chemicals and immune system. Toxicol Appl Pharmacol. 2005;207:320-8.

45. Fareed M, Pathak MK, Bihari V, Mudiam MKR, Patel DK, Mathur N, et al. Hematological and biochemical alterations in sprayers occupationally exposed to mixture of pesticides at a mango plantation in Lucknow. India Toxicol Environ Chem. 2010;92:1919-28.

46. Fareed M, Pathak MK, Bihari V, Kamal R, Srivastava AK, Kesavachandran CN. Adverse respiratory health and hematological alterations among agricultural workers occupationally exposed to organophosphate pesticides: a crosssectional study in North India. PLoS One. 2013;8:e69755.

47. London L, Beseler C, Bouchard MF, Bellinger DC, Colosio C, Grandjean P, et al. Neurobehavioral and neurodevelopmental effects of pesticide exposures. Neurotoxicol. 2012:33:887-96.

48. Naidoo S, London L, Burdorf A, Naidoo R, Kromhout H. Spontaneous miscarriages and infant deaths among female farmers in rural South Africa. Scand J Work Env Health. 2011;37:227-36.

49. Penagos HG. Contact dermatitis caused by pesticides among banana plantation workers in Panama. Int J Occup Environ Health. 2002;8:14-8.

50. Andersson L, Claeson AS, Nyberg L, Stenberg B, Nordin S. Brain responses to olfactory and trigeminal exposure in idiopathic environmental illness (IEI) attributed to smells_an fMRI study. J Psychosom Res. 2014;77:401-8.

51. De Luca C, Scordo MG, Cesareo E, Pastore S, Mariani S, Maiani G, et al. Biological definition of multiple chemical sensitivity from redox state and cytokine profiling and not from polymorphisms of xenobiotic-metabolizing enzymes. Toxicol Appl Pharmacol. 2010;248:285-92.

52. McKeown-Eyssen G, Baines C, Cole DE, Riley N, Tyndale RF, Marshall L, et al. Case-control study of genotypes in multiple chemical sensitivity: CYP2D6, NAT1, NAT2, PON1, PON2 and MTHFR. Int J Epidemiol. 2004;33:971-8.

53. Orriols R, Costa R, Cuberas G, Jacas C, Castell J, Sunyer J. Brain dysfunction in multiple chemical sensitivity. J Neurol Sci. 2009;287:72-8.

54. Hojo S, Tokiya M, Mizuki M, Miyata M, Kanatani KT, Takagi A, et al. Development and evaluation of an electromagnetic hypersensitivity questionnaire for Japanese people. Bioelectromagnetics. 2016;37:353-72.

Ready to submit your research? Choose BMC and benefit from:

- fast, convenient online submission

- thorough peer review by experienced researchers in your field

- rapid publication on acceptance

- support for research data, including large and complex data types

- gold Open Access which fosters wider collaboration and increased citations

- maximum visibility for your research: over $100 \mathrm{M}$ website views per year

At BMC, research is always in progress.

Learn more biomedcentral.com/submissions 